\title{
Entre memória e esquecimento: as temporalidades da história, das mídias e das experiências
}

\author{
Roger CHARTIER ${ }^{1}$
}

Resumo:

Este trabalho é resultado da conferência de mesmo título apresentada pelo autor na abertura do XII Encontro Nacional de História da Mídia (Alcar 2019), realizado em Natal, na Universidade Federal do Rio Grande do Norte (UFRN), Brasil.

Palavras-chave:

História e memória. Memória e esquecimento. História da mídia.

\section{Between memory and oblivion: history, temporality, experience and media}

\begin{abstract}
:
This paper is the outcome of a conference with the same title presented by the author at the launching of the XII Media History National Meeting - Encontro Nacional de História da Mídia- (Alcar 2019), held in Natal, at Universidade Federal do Rio Grande do Norte (UFRN), Brazil.
\end{abstract}

Keywords:

History and memory. Memory and oblivion. Media history.

Entre memoria y olvido:

las temporalidades de la historia, los medios y las experiencias

\section{Resumen:}

Este documento es el resultado de una conferencia del mismo título presentada por el autor en la apertura de la XII Reunión Nacional de Historia de los Medios (Alcar 2019), celebrada en Natal, en la Universidad Federal de Río Grande del Norte (UFRN), Brasil.

Palabras clave:

Historia y memoria. Memoria y olvido. Historia de los medios.

Introdução

Nesta conferência, quero discutir a partir de uma perspectiva histórica os desafios aos conceitos e experiências da temporalidade pela aceleração da comunicação. Devo confessar que por muito tempo tive reticência frente à noção de "aceleração", que me parecia uma fórmula vaga tornada lugar comum. Revisei minha relutância por três razões.

\footnotetext{
1 Professor no Collège de France desde 2007, na disciplina Escrita e Culturas na Europa Moderna. Atuou como professor convidado em diversas universidades, entre elas, Universidade da Pensilvânia. Entre os livros publicados no Brasil, estão: A história ou a leitura do tempo; Inscrever e apagar: cultura escrita e literatura (séculos XI-XVIII); Os desafios da escrita; Cardenio entre Cervantes e Shakespeare: História de uma peça perdida; e A mão do autor e a mente do editor.
} 
A primeira se liga com a relação estabelecida entre a aceleração do tempo histórico e o apagamento da memória nas sociedades contemporâneas. Esta observação foi o ponto de partida da imponente obra coletiva dirigida por Nora, escrita entre 1984 e 1992: os sete volumes dos Lieux de mémoire. Os dois primeiros parágrafos do prólogo que abre a série vinculam a perda da memória com a aceleração do tempo. Paradoxalmente, Nora (1993) considera a busca (e a história) dos lugares de memória como um efeito do afastamento do passado:

\begin{abstract}
Aceleração da história. Para além da metáfora, é preciso ter a noção do que a expressão significa: uma oscilação cada vez mais rápida de um passado definitivamente morto, a percepção global de qualquer coisa como desaparecida - uma ruptura de equilíbrio. [...] A curiosidade pelos lugares onde a memória se cristaliza e se refugia está ligada a este momento particular de nossa história. Há locais de memória porque não há mais meios de memória (NORA, 1993, p. 7).
\end{abstract}

Uma segunda razão que dá relevância à noção de aceleração origina-se em duas obras filosóficas. Com seu livro Vitesse e politique (publicado em 1977 e traduzido em 1996 como Velocidade e política), Virilio (1996) deslocou a atenção desde os efeitos produzidos pela nova velocidade dos transportes nos séculos XIX e XX até às transmissões instantâneas permitidas pela revolução das comunicações eletrônicas. Numa conversa com Guilherme Soares dos Santos, publicada pelo Le Monde Diplomatique em 2011, Virilio (2011), que era arquiteto e urbanista, enfatiza os dois efeitos essenciais do poder da tirania da velocidade. O primeiro é o fim do tempo humano: "E, claro, com a televisão, os computadores e a Internet, nós entramos numa fase que hoje atinge o seu limite; a velocidade da luz em que o tempo humano, o tempo da negociação, da especulação, em que a inteligência do homem, do especulador, dos cotadores é ultrapassada pelos automatismos" (VIRILIO, 2011, não paginado). A humanidade entrou no "tempo-máquina", que é uma das formas de "matematização do mundo" e do que Supiot (2015) descreve como "la gouvernance par les nombres". Segundo efeito: a desaparição do tempo local. Em entrevista a Fernando Eichenberg, Virilio (2000) afirmou:

A História se escreve no tempo local, no tempo das regiões, o dos países. No entanto, hoje, conta o tempo global, o tempo mundial, aquilo a que os astrônomos chamam de tempo astronômico. [...] É o fím de um tempo histórico. O tempo histórico de Fernand Braudel, de grandes historiadores, era o tempo local. Hoje o tempo é global. Não se pode entender a globalização, o mercado único, sem pensar que há um tempo único (VIRILIO, 2000, não paginado). 
Virilio (2000) nos convida assim a voltar de maneira crítica à construção temporal proposta por Fernand Braudel como pedra de toque das ciências sociais. A aceleração das percepções da realidade é o tema fundamental do trabalho de Rosa (2019) e de seu primeiro livro, publicado em alemão em 2005 e traduzido para o português em 2019 como Aceleração. A transformação das estruturas temporais na modernidade. Como o indica Tziminadis (2017), que dialogou com Rosa em 2017, o argumento central do livro é um paradoxo: "A despeito do crescente aparato técnico utilizado para a economia de tempo na produção, nos transportes e na comunicação, a sociedade moderna é acometida por uma tendência paralela de escassez temporal" (TZIMINADIS, 2017, p. 366). A consequência é a alienação produzida pela discrepância entre a aceleração dos processos sociais e, por outro lado, algumas formas das experiências humanas. Esta discrepância é o objeto do segundo livro de Rosa (2010), Alienation and acceleration. Rosa enfatiza os efeitos da aceleração alienante no seu diálogo com Tziminadis (2017):

\footnotetext{
A sociedade moderna pode manter sua própria estrutura apenas através de aceleração, crescimento e inovação, o que significa que o mundo como um todo, em sua materialidade, é posto sob pressão para dinamizar-se: pessoas, dinheiro, bens e matérias primas são postas em movimento. Por outro lado, podem existir tradições culturais, populações tradicionais que não conseguem acelerar senão ao preço de sua própria destruição (TZIMINADIS, 2017, p. 372).
}

O tempo ecológico da natureza, o tempo das deliberações da democracia, o tempo dos corpos e das mentes se encontram assim dessincronizados do tempo das comunicações. A reflexão de Rosa (apud TZIMINADIS, 2017) nos propõe outro convite: pensar as temporalidades não como exteriores aos homens, mas bem como estruturas das experiências que o sociólogo ou o historiador não pode separar das desigualdades sociais. Bourdieu (2001) nos ajudará para compreender a pluralidade social das maneiras de temporalizar-se.

Uma terceira razão para pensar a aceleração se localiza no meu próprio campo de pesquisa: a história das leituras. Uma das transformações mais importantes das práticas de leitura dos adolescentes frente às telas é, de fato, a leitura acelerada. As investigações sociológicas mostram que a leitura dos textos eletrônicos, quaisquer que sejam, é uma leitura apressada, que busca só informações ou que deseja chegar o mais rápido possível na conclusão da análise e no desenlace da narração. A lógica da aceleração caracteriza a relação da geração analógica com todos os objetos culturais, não só livros, mas também 
séries e filmes, assistidos no dobro da velocidade normal, ou ainda em faixas de música reduzidas a um minuto. Estes usos impacientes, associados com a falta de questionamento da veracidade dos conteúdos divulgados, desafiam as operações mais lentas do conhecimento crítico necessário para a compreensão tanto do presente como do passado. Refletir sobre as diferenças e os laços entre história, ficção e memória se torna uma necessidade imprescindível.

\title{
Os tempos da história e os tempos da ficção
}

A especificidade da história reside na sua capacidade de articular as diferentes temporalidades que se encontram contemporâneas em cada momento histórico. É semelhante construção temporal que sustentava todo o edifício da história e, além dela, da ciência social na perspectiva de Braudel (2011). Segundo ele, em seu artigo História e Sociologia, publicado originalmente em 1958:

\begin{abstract}
A história situa-se em patamares diferentes; diria de bom grado três patamares, mas isto é modo de falar, muito simplista [...] Na superfície, uma história factual se inscreve no tempo curto: é uma micro-história. A meia encosta, uma história conjuntural segue um ritmo mais largo e mais lento. Foi estudada até aqui sobretudo estudado no plano da vida material, dos ciclos ou interciclos econômicos [...] Para além desse 'recitativo' da conjuntura, a história estrutural, ou de longa duração, coloca em jogo séculos inteiros; está no limite daquilo do móvel e do imóvel, e por seus valores fixos há muito tempo, faz figura de invariante em face de outras histórias, mais vivas a se escoar e a se consumar, e que em suma, gravitam em torno dela (BRAUDEL, 1992, p. 104-105).
\end{abstract}

Parece-me que hoje em dia duas questões surgem em meio a esse poderoso modelo das durações sobrepostas. Em primeiro lugar, serão elas tão irredutivelmente diferentes uma da outra? Não se deve considerar, como faz Ricœur (2011, v. 1, p. 296) em seu livro Temps et récit, Tempo e narrativa, que "a própria noção de história de longo termo deriva do acontecimento dramático, no sentido [aristotélico] de acontecimento-armado-naintriga" e que, por esse fato, os três tempos braudelianos referem-se a uma mesma matriz temporal? A longa duração do mar Mediterrâneo deveria ser entendida como construída segundo as fórmulas que relacionam a temporalidade dos relatos com o tempo subjetivo dos indivíduos. Na escrita do historiador, o tempo do mar e o tempo do rei estão construídos segundo as mesmas modalidades narrativas. Ricœur (2011) opõe assim a homologia das temporalidades a sua suposta heterogeneidade. 
Por outro lado, devemos encerrar a noção de evento dentro de sua definição tradicional que a vincula à duração breve, às decisões conscientes, aos fatos políticos? Num ensaio dedicado a Nietzsche, Nietzsche, a genealogia e a história, publicado em 1971, Foucault (1979) estabeleceu uma estreita ligação entre uma crítica devastadora à noção de origem, que supõe a existência do evento antes de seu advento, e uma profunda reformulação do conceito de acontecimento. Para ele, o evento deve ser situado, nem na continuidade ideal da história hegeliana, que o apaga, nem nos acidentes do curso da história ou das escolhas dos indivíduos, como quer a história tradicional, e, sim, como o sugere a história "efetiva" de Nietzsche, dentro do que aparece como o mais oposto ao tempo curto da superfície da história, ou seja, as transformações das relações de dominação:

Por evento, se deve entender não uma decisão, um tratado, um reinado ou uma batalha, mas a inversão de uma relação de forças, a confiscação dum poder, um vocabulário que torna contra aqueles que o usaram, uma dominação que se debilita, se relaxa, envenena a si mesma, à medida que cresce outra, mascarada. As forças que operam na história não obedecem nem ao destino nem a uma mecânica, mas aos azares da luta. Não aparecem como as formas sucessivas de uma intenção primordial; tampouco adotam a forma de um resultado necessário. Sempre estas forças aparecem nas circunstâncias singulares do evento (FOUCAULT, 1979, p. 28).

Se o evento, nessa leitura nietzschiana, permanece violento, inesperado, não designa mais a espuma dos fatos. Faz surgir e instaura as rupturas e descontinuidades mais fundamentais.

Qualquer que seja sua construção, o tempo da história não é a temporalidade própria das obras nascidas da imaginação estética. Vejamos dois exemplos dos tempos da ficção: o teatro no século XVII, o romance no século XX. Quando publicaram, em 1623, um livro in-fólio que pela primeira vez reunia as obras teatrais de Shakespeare, os dois editores, Heminges e Condell (que haviam sido, como o próprio dramaturgo, atores e proprietários na companhia do Rei, os King's Men), decidiram repartir as trinta e seis obras impressas no livro em três categorias: "comédias", "histórias", "tragédias". Se a primeira e a terceira retomavam a divisão clássica entre os dois gêneros da poética teatral aristotélica, a segunda ("histórias") introduzia uma nova categoria que no fólio compreendia dez obras que contavam a história dos reis da Inglaterra entre King John e Henry the Eight. 
Ao publicar as dez obras segundo a cronologia dos reinados, Heminges e Condell as transformaram em uma narrativa dramática construída segundo uma concepção linear do tempo, que era a que fundamentava também a escrita das crônicas empregadas por Shakespeare na composição de seus próprios textos, tais como as Chronicles of England, de Hall, Stow, Grafton ou Holinshed. Antes da publicação no fólio, as "histórias" (ou pelo menos algumas delas) foram as obras de Shakespeare de maior sucesso. Elas configuraram as "experiências coletivas físicas e mentais" - como escreve Greenblatt (1988, p. 6) - de seus espectadores e leitores graças a suas encenações teatrais e a suas numerosas edições in-quarto publicadas antes do fólio.

Mas a história representada sobre os palcos não era a história dos cronistas: era uma história aberta aos anacronismos, uma história governada por uma cronologia propriamente teatral, e não pela cronologia dos acontecimentos tais como se sucederam. A história representada sobre os palcos distorce as crônicas e transfigura os acontecimentos para propor à imaginação dos espectadores representações ambíguas do passado, caracterizadas pelas incertezas, pelas contradições e pela impossibilidade de dar um sentido único aos eventos. O tempo das "histories" representadas nos teatros não é somente o tempo dos acontecimentos, das decisões, das vontades, das intenções dos indivíduos. É também o tempo inexorável da roda da fortuna que faz suceder inevitavelmente a queda ao triunfo e, mais essencialmente, o tempo de Deus que os homens não podem, não devem decifrar ou compreender, salvo quando são profetas inspirados que falam palavras que não são as suas - por exemplo, o bispo Carlisle, em Richard II, ou o arcebispo Cranmer, em Henry the Eight. Talvez seja nessa distorção das realidades históricas tal como as estabelecem os historiadores, nessa instabilidade e opacidade do sentido dos acontecimentos, que resida a força única das apropriações e representações teatrais do passado ou, mais frequentemente, das ficções literárias.

No século XIX, uma vez estabelecido o sentido moderno da palavra "literatura", não mais definida como "erudição", como o faziam os dicionários do século XVII, mas como o corpus de criações estéticas que supõem a originalidade das obras, a singularidade da escrita e a propriedade do autor, a escritura literária proclamou ser a "verdadeira" história, a história ignorada pelos historiadores do tempo fascinados pelos grandes eventos e pelos indivíduos poderosos. À distância dessa fascinação, o romance devia assumir a tarefa de descrever a sociedade inteira, de propor, como indicava Manzoni (apud GINZBURG, 2017) em 1845, no seu livro Del romanze storico, pensando em seu próprio romance I promessi sposi, 
não é somente um relato cronológico de fatos políticos e militares e, por exceção, de algum acontecimento extraordinário de outro gênero; mas sim uma representação mais geral do estado da humanidade num tempo, num lugar naturalmente mais circunscritos do que aquele em que costumam se estender os trabalhos de história; no sentido mais usual do vocábulo (MANZONI, 1845 apud GINZBURG, 2017, p. 324).

O objetivo do romance era apresentar "numa forma nova e especial, uma história mais rica, mais variada, mais completa do que a que se encontra nas obras a que se dá esse nome, mais comumente e como por antonomásia" (MANZONI, 1845 apud GINZBURG, 2017, p. 324). O romance devia assim dar a conhecer:

[...] costumes, opiniões, tanto gerais ou particulares a esta ou àquela classe de homens; efeitos privados dos acontecimentos públicos que se chamam mais propriamente de históricos, e das leis ou da vontade dos poderosos, qualquer que seja a maneira como e tenham manifestado; em resumo, tudo o havia de mais característico, em todas as condições da vida e nas relações de uma com as outras numa sociedade dada, num tempo dado (MANZONI, 1845 apud GINZBURG, 2017, p. 324).

Nessa perspectiva, o romancista se torna o verdadeiro historiador que mostra as diferenças de temporalidade que atravessam uma sociedade. É o que afirma Balzac (2011) no primeiro parágrafo do seu romance Les illusions perdues, Ilusões perdidas, publicado em 1843, que apresenta a obra como uma "grande pequena história". "Pequena história" porque começa com a descrição de uma pequena tipografia numa pequena cidade provincial francesa:

$\mathrm{Na}$ época em que começa esta história, a prensa de Stanhope e os rolos de tintagem ainda não funcionavam nas pequenas tipografias de província. Apesar da especialidade que a leva ser comparada com a tipografia parisiense, a cidade de Angoulême ainda usava as prensas de madeira (BALZAC, 2011, p. 27).

"Pequena história", mas "grande história" também porque o contraste técnico entre prensas de madeira e prensas mecânicas é a expressão e a matriz dos destinos tanto individuais quanto coletivos que conduzem da província desprezada até Paris, capital devoradora e decepcionante onde se perdem as ilusões. Durante a Restauration, entre 1815 e 1830, com certeza Angoulême e Paris compartilham o mesmo calendário, porém não são contemporâneas.

Quando a história dos historiadores abandonou seus ídolos tradicionais em favor das conjunturas econômicas e demográficas, das hierarquias sociais, das crenças 
coletivas, a literatura enfatizou as singularidades e as diferenças. Escrever as vidas únicas de indivíduos particulares tornou-se um gênero favorito. Borges (2014) nomeou Marcel Schwob como seu precursor em sua Biblioteca pessoal (livro publicado em 1985):

Em 1935, escrevi um livro ingênuo que se chamava Historia universal de la infâmia. Uma das suas numerosas fontes foi o livro de Schwob. [...] Suas Vidas imaginárias datam de 1896. Para escrevê-lo, inventou um curioso método. Os protagonistas são reais; os fatos podem ser fabulosos e muitas vezes fantásticos. O sabor particular deste livro reside neste vaivém (BORGES, 2014, p. 69-70).

O "curioso método" de Schwob (2011) consistia em separar radicalmente os destinos singulares das ideias universais, em privilegiar "o sentimento individual" e em libertar a escrita biográfica das exigências da verdade histórica. Schwob (2011) define a arte, seja literatura ou pintura, em oposição à história de seu tempo, interessada nas ideias universais: "A ciência histórica nos deixa na incerteza acerca dos indivíduos. Revela-nos somente os pontos em que eles foram vinculados a ações universais", enquanto que a arte "é contrária às ideias universais, descreve apenas o individual, deseja apenas o único. Não classifica; desclassifica" (SCHWOB, 2011, p. 47). Então, a arte do biógrafo, tal como a arte do pintor japonês Hokusai, consiste "a efetuar a milagrosa mutação da semelhança em diversidade", a "tornar individual aquilo que há de mais genérico" (SCHWOB, 2011, p. 50-54). A busca das "próprias esquisitices" ou das "anomalias" de cada homem não supõe a conformidade à realidade: ao biógrafo,

não lhe cabe a preocupação de ser verdadeiro; ele deve criar em meio a um caos de traços humanos [...] Em meio a esse grosseiro conjunto, o biógrafo seleciona o material para compor uma forma que não se pareça com nenhuma outra. Não precisa ser igual àquela criada outrora por um deus superior, desde que seja única, como toda criação (SCHWOB, 2011, p. 55).

O gênero aparentemente o mais histórico, a biografia, deve afastar-se da história para aproximar-se duma realidade mais profunda, mais essencial, contando, como o faz Schwob (2011, p. 56) no seu livro, "as existências únicas dos homens, quer tenham sido divinos, medíocres ou criminosos". Assim, o ideal da biografia ou, mais geralmente, da literatura é "diferenciar ao infinito" (SCHWOB, 2011, p. 50).

Seguindo o caminho assim aberto, a literatura no século XX se apoderou do que os novos ídolos da história (populações, economias, sociedades) ignoravam, desprezavam ou apagavam, ou seja, as "vidas" sempre únicas, frágeis, obscuras. Nos romances, esta 
atenção se vincula com as "vidas minúsculas" ou as "histórias ínfimas", como nos oito capítulos do livro de Michon (2004), Vies minuscules, publicado em 1984 e traduzido para o português em 2004. Mas as existências anônimas, os destinos ignorados se encontram também nos arquivos, como se os documentos geralmente tratados estatisticamente pelos historiadores preservassem traços breves, fragmentados, poéticos das vidas singulares. É a "história” dessas vidas minúsculas que Foucault (2006) desejava fazer presente no seu projeto de "antologias de existências", que apresentou em 1977 num ensaio pensado como uma introdução geral de uma antologia de documentos dos séculos XVII e XVIII, intitulado La vie des hommes infâmes, $A$ vida dos homens infames ("infames" por serem sem fama, sem gloria): "Vidas singulares, tornadas, por não sei quais acasos, estranhos poemas, eis o que eu quis juntar em uma espécie de herbário" (FOUCAULT, 2006, p. 204).

Invertendo o procedimento de Schwob (2011), é em “existências reais", em “vidas breves, encontradas por acaso em livros ou documentos" (relatórios de polícia, registros de internamento, petições ao rei, cartas régias com ordem de prisão), que Foucault (2006) localizava "o efeito misto de beleza e de terror" produzido por estas "vidas de algumas linhas ou de algumas páginas, desventuras e aventuras sem nome, juntadas em um punhado de palavras" (FOUCAULT, 2006, p. 203). Nessas vidas das quais não se conhece geralmente nada mais que os rastros breves, enigmáticos, escritos pelas instituições, Foucault (2006) encontrava existências perdidas, que nunca haveriam sido conhecidas sem o momento quando se chocaram com o poder ou quando tentaram utilizar suas forças: "Quis, em suma, reunir alguns rudimentos para uma lenda dos homens obscuros, a partir dos discursos que, na desgraça ou na raiva, eles trocam com o poder" (FOUCAULT, 2006, p. 208). A vontade de dar visibilidade aos destinos singulares está situada aqui no seu limite: "a existência desses homens e dessas mulheres remete exatamente ao que deles foi dito; do que eles foram ou do que fizeram nada subsiste, exceto em poucas frases" (FOUCAULT, 2006, p. 209). Nesse sentido, se inverte a perspectiva que localiza o real das existências na ficção literária, porque "ali se produz um certo equívoco do fictício e do real" (FOUCAULT, 2006, p. 108). Os indivíduos que realmente sofreram ou esperaram "não têm e nunca terão existência senão ao abrigo precário dessas palavras": "essa pura existência verbal faz desses infelizes ou desses facínoras seres quase fictícios" (FOUCAULT, 2006, p. 209).

Nesses casos, a literatura não só sujeita as temporalidades da história às suas próprias regras, mas também opõe o tempo irredutivelmente singular de cada existência 
humana ao tempo coletivo das instituições, dos destinos comuns, das representações compartilhadas.

\section{Os tempos da memória e da experiência}

É uma outra oposição que propõe Ricœur (2007) no seu último livro, A memória, a história e o esquecimento. Ricœur (2007) estabelece uma série de distinções essenciais entre estas duas formas de presença do passado no presente que asseguram, por um lado, o trabalho da memória, quando o indivíduo "desce à sua memória", como escreveu Borges, e, por outro lado, a operação historiográfica. A primeira diferença é a que distingue o testemunho do documento. Se o primeiro é inseparável da testemunha e da credibilidade outorgada a suas palavras, o segundo permite o acesso a conhecimentos que foram recordações de alguém. À estrutura fiduciária do testemunho, que implica a confiança, se opõe a natureza indiciária do documento, submetido aos critérios objetivos da prova. Uma segunda distinção opõe a instantaneidade da memória e a construção explicativa da história, seja qual for a escala de análise dos fenômenos históricos ou o modelo de inteligibilidade escolhido, sejam as explicações que estabelecem as determinações desconhecidas dos atores, sejam as explicações que privilegiam suas estratégias explícitas e conscientes. Depreende-se daí uma terceira diferença, entre o reconhecimento do passado possibilitado pela memória e sua representação, no sentido de "ter o lugar de", assegurada pelo relato histórico.

A instantaneidade da memória, surgimento das lembranças ou resultado da anamnese, se encontra assim diferenciada das operações específicas que fundamentam tanto a intenção de verdade quanto a prática crítica da história. Em nosso tempo, em que proliferam falsificações e falsas verdades, parece-me importante entender a afirmação de Certeau (2008) a respeito da capacidade da história de produzir enunciados "científicos", se entendermos por isso "a possibilidade de estabelecer um conjunto de regras que possibilitem 'controlar' operações adequadas na produção de objetos determinados" (CERTEAU, 2008, p. 109). São essas operações e regras que permitem dar crédito científico à representação histórica do passado e rejeitar a suspeita de relativismo ou ceticismo que nasce do uso pela escrita historiográfica das formas "literárias" (estruturas narrativas, tropos retóricos, figuras metafóricas).

Essas diferenças fundamentais entre verdade e fábula, entre saber e ficção, entre história e memória, não devem fazer esquecer as dependências que vinculam as percepções do tempo com as formas da escrita da história, as experiências das 
temporalidades com as modalidades do conhecimento do passado. Segundo Koselleck (2014), as três categorias da experiência (a observação do que não se repete, a percepção da repetição e o saber das transformações que escapam à experiência imediata) correspondem a três maneiras de escrever a história: a crônica que registra o acontecimento único, a história que desenvolve comparações, analogias e paralelismos tal como a historiografia do século das Luzes, e a história entendida como reescrita, ou seja, como fundada nos métodos e técnicas que permitem um conhecimento crítico que contribui para um progresso cognitivo acumulado (KOSELLECK, 2014), que é a história como ciência histórica tal como se fundamentou a partir do século XIX e tal como a praticamos hoje em dia.

Tanto o tempo próprio da memória como o tempo diferenciado organizado pelas várias experiências das durações são localizados numa perspectiva fenomenológica compartilhada por Ricœur (2007) e Koselleck (2014). Como historiadores ou sociólogos, devemos situar essas percepções individuais nas diferenças entre classes e meios sociais. Bourdieu (2001), em seu livro Meditações pascalianas, enfatiza que a relação com o tempo é uma das propriedades sociais mais desigualmente distribuídas entre os indivíduos: "De fato, para romper verdadeiramente com a ilusão universalista da análise de essência, seria preciso descrever as diferentes maneiras de se temporalizar, referindoas às suas condições econômicas e sociais de possibilidade" (BOURDIEU, 2001, p. 273). Cita Bourdieu (2001, p. 272) várias modalidades de temporalizar-se: ser dono do seu próprio tempo, ou controlar o tempo dos outros ("o todo-poderoso é aquele que não espera, ao contrário, faz-se os esperar"), ou não ter domínio do tempo, como no caso dos "homens sem futuro", que,

para escapar ao não-tempo de uma vida onde não acontece nada e da qual não se pode esperar nada, e para se sentir existir, recorrem a atividades as quais, como as apostas no jóquei, a loteria esportiva, o jogo do bicho e os demais jogos de azar em todos os bairros miseráveis e favelas do mundo, permitem desguiar do tempo anulado de uma vida sem justificativa, e, sobretudo, sem investimento possível (BOURDIEU, 2001, p. 272).

Uma vida na qual não existe nenhuma relação racional entre oportunidades e expectativas, entre possibilidades efetivas e esperanças ilusórias.

Essas diferentes possibilidades (ou impossibilidades) são várias modalidades incorporadas da relação com o tempo que expressam o poder dos dominadores e a impotência dos dominados. Então, as variadas temporalidades não devem ser somente consideradas como durações nas quais se localizam os diferentes fenômenos históricos, 
nem como categorias universalmente compartilhadas numa sociedade dada ou como invariantes antropológicas próprias da humanidade inteira. São formas de "temporalizarse" que asseguram e mostram o poder de alguns (sobre o presente e o futuro, sobre si mesmo ou sobre os outros) e que levam outros ao desespero.

\section{O esquecimento}

Semelhante discordância dos tempos pode nos conduzir a uma última reflexão sobre as relações entre temporalidades e esquecimento. Trata-se então de considerar o esquecimento, não como o cancelamento do tempo, mas bem como sua condição de possibilidade. A afirmação tem várias expressões. Em primeiro lugar, uma expressão filosófica com Heidegger (2012, p. 437) no Ser e tempo: “Assim como a expectativa só é possível na base de um esperar, também a lembrança [Erinnerung] só é possível na base de um esquecer, e não o contrário", e isso porque o passado não é uma ausência radical, senão um "ter sido" preservado. Ricœur (2007, p. 450-451) comenta: "Ninguém pode fazer com que o que não é mais não tenha sido. É ao passado como tendo sido que se vincula esse esquecimento que, como diz Heidegger, condiciona a lembrança. Compreende-se o paradoxo aparente se por esquecimento se entende o imemorial recurso e não a inexorável destruição".

Uma segunda expressão do paradoxo se encontra na ficção de Borges Funes, o memorioso, publicado em 1979, que mostra o perigo, o espectro ou o fantasma duma memória integral, absoluta, que nada esquece. No seu conto, Borges entrelaça dois motivos: o esquecimento como condição do pensamento, enquanto pensar é um processo de abstração e de generalização ("Funes, não o podemos esquecer, era quase incapaz de ideias gerais, platônicas") e o esquecimento como condição do sono ("Para ele, dormir era muito difícil. Dormir é distrair-se do mundo"). A opressão da memória absoluta impede tanto o sono quanto o pensamento que supõem, tanto um como o outro, a capacidade de esquecer. "Eu, sozinho, tenho mais lembranças que terão tido todos os homens desde que o mundo é mundo", declara Funes. Mas lembrar-se de tudo não é pensar, pois "pensar é esquecer diferenças e generalizar, abstrair. No mundo entulhado de Funes, não havia senão detalhes quase imediatos" (BORGES, 2015, p. 108). Borges (1993, v. 1, p. 1584-1585) comenta numa entrevista: "Funes morre muito jovem, esmagado por aquela memória que um deus poderia tolerar, mas não um homem".

No trabalho dos historiadores, esta tensão entre recordar e esquecer tomou a forma de uma trajetória cronológica que leva das técnicas da memória medievais, que 
constituíam bibliotecas mentais donde os trechos de discursos memorizados se localizavam nos vários lugares das arquiteturas da memória, até as próteses escritas da memória: arquivos, livros, bibliotecas e, hoje, as memórias dos computadores. Contudo, a tarefa de conservação foi sempre acompanhada pelo desejo do apagamento, da inscrição efêmera, da escrita sem traços. É o que procuravam nos séculos XVI e XVII as "writing tables" na Inglaterra e os "librillos de memoria" na Espanha, assim definidos pelo Dicionário da Real Academia em 1734 (LIBRILLOS..., 1734):

pequeno livro que temos o hábito de levar no bolso, cujas folhas são cobertas com um revestimento e são brancas. No livrete se incluiu uma pena de metal na ponta da qual se insere um fino grafite de lápis com o qual se anota tudo o que não se quer confiar à fragilidade da memória, e que se apaga em seguida, para que as folhas possam servir novamente (LIBRILLOS..., 1734, p. 400).

As folhas recobertas com uma fina película feita de gesso, cola e verniz permitiam escrever, apagar e reescrever (CHARTIER, 2006).

É também o que permitia o "Wunderblock" ou "bloco mágico" na Viena do século XIX sobre o qual a escrita, traçada com um estilete, podia ser apagada, deixando o bloco disponível para uma nova escrita. Mas, como observou Freud (2011), se expuséssemos o bloco a uma luz apropriada, se tornava possível decifrar os traços deixados pela escrita, embora ela tivesse sido apagada. O bloco mágico forneceu a Freud (2011), em 1925, uma metáfora material da própria estrutura do aparelho psíquico: como a lousa, o sistema percepção-consciência tem uma capacidade ilimitada de receber excitações, porém sem inscrição durável; como o "bloco mágico", o sistema mnésico conserva traços duradouros, recuperáveis, mas situados no inconsciente.

Semelhante tensão entre a proliferação dos discursos e os procedimentos encarregados de assegurar sua "rarefação" se encontram no princípio da aula inaugural no Collège de France de Foucault (2012), A ordem do discurso:

Suponho que em toda sociedade a produção do discurso é ao mesmo tempo controlada, selecionada, organizada e redistribuída por certo número de procedimentos que têm por função conjurar seus poderes e perigos, dominar seu acontecimento aleatório, esquivar sua pesada e temível materialidade (FOUCAULT, 2012, p. 8-9).

Para ele, os três tipos de procedimentos assegurando esta rarefação dos discursos são, em primeiro lugar, os sistemas de exclusão que definem as palavras proibidas, que separam loucura e razão e que afirmam a vontade de verdade de certos discursos; em 
seguida, os princípios de classificação, de ordenação e de distribuição dos discursos (assim, as noções de autor ou de disciplina); e, finalmente, as formas de apropriação ou confiscação dos discursos que não permitem "que todo mundo tenha acesso a eles" (FOUCAULT, 2012, p. 37). O programa de análise genealógico e crítico dos procedimentos assegurando a rarefação dos discursos expressava de maneira contundente dois temores contraditórios que obcecaram a Europa da primeira era moderna e que ainda nos atormentam: por um lado, o medo ante a proliferação indomável dos escritos, a multiplicação dos textos inúteis, a desordem do discurso e, por outro, o medo da perda, da falta, do esquecimento.

Apoiado sobre Heidegger, Borges e Freud, o conceito de "esquecimento de reserva", "oubli de réserve", proposto por Ricœur (2007) ajuda a ultrapassar a contradição. Segundo ele, existe uma polaridade entre duas grandes figuras do esquecimento: o esquecimento "profundo", que é perda, desaparição, destruição dos traços, tanto documentais como psíquicas, e o esquecimento que é preservação, latência e recurso pela memória. Em relação a essa segunda figura do esquecimento, Ricœur indica, numa conferência pronunciada em Budapeste em 2003: “O esquecimento tem um polo ativo ligado ao processo de rememoração, essa busca para reencontrar as memórias perdidas, que, embora tornadas indisponíveis, não estão realmente desaparecidas”. Esse trabalho da rememoração tem várias modalidades: a cura da psicanálise, a reapropriação do passado histórico, ou as políticas da memória que permitem anistia sem amnésia (RICOEUR, 2003).

Quero terminar esta palestra na companhia de Ricœur. As reivindicações das memórias, individuais ou coletivas, levaram ao questionamento das pretensões do saber histórico, considerado frio e inerte diante da relação viva que leva à apreensão do passado no imediatismo de sua reminiscência. De fato, a história enfrenta um profundo desafio quando a memória ou a literatura se encarrega da representação autêntica, verdadeira do passado e opõe a força e a autoridade da lembrança ou da ficção ao "desconforto na historiografia”, segundo uma expressão de Yerushalmi (1992). É a razão pela qual a história e mais geralmente as ciências humanas e sociais devem reafirmar a especificidade do regime de conhecimento que lhes é próprio. Este regime implica o exercício da crítica, a confrontação entre as razões dos atores e as determinações que eles ignoram, e a produção de um saber cujas operações e resultados estão submetidos a critérios de prova aceitos por uma comunidade científica. Ao reafirmar sua diferença em relação a discursos potentes, ficcionais ou memoriais, e também em relação a falsificações das realidades 
presentes ou passadas, as ciências da sociedade assumem a responsabilidade que lhes compete: fazer inteligíveis as heranças e as descontinuidades que nos tornaram o que somos tanto como indivíduos quanto como sociedade.

A verdade histórica é, segundo Ricœur (2007), a condição para que possa estabelecer-se uma "memória equitativa" - "equitativa" porque obriga as memórias particulares a confrontar-se com uma representação do passado situada na ordem de um conhecimento controlável e universalmente aceitável. Contudo, a história não pode ignorar as violências que se esforçaram e se esforçam em fazer desaparecer, não só as vítimas das tiranias, mas também a possibilidade de que suas existências sejam recordadas e as razões de seu martírio conhecidas. Nesse sentido, a história sempre deve ser o saber que desmascara as falsificações, que rechaça as negações do que foi ou do que é, que estabelece um conhecimento comprovado. Assim, pode contribuir a apaziguar as feridas que deixou em nosso presente um passado que foi amiúde injusto e cruel. Assim, pode desempenhar um papel cívico e ético.

As mutações políticas que aconteceram recentemente em ambos os lados do Atlântico ou no norte e no sul das Américas obrigam a refletir com urgência e ansiedade sobre a relação entre autoridade e verdade. Essas mutações mostram os perigos que ameaçam tanto a memória como a história. A memória, porque aproveitam o desconhecimento do passado para impor as representações de uma realidade que nunca foi. A história, porque opõem ao conhecimento verdadeiro as falsificações dos fatos e as manipulações das opiniões. Em ambos os casos, é a noção de verdade que se encontra desafiada, ameaçada, descartada. Assim se desfaz o vínculo antigo entre verdade e democracia, entre o uso da razão baseado sobre os conhecimentos e a decisão política. Tal ruptura constitui um perigo mortal para as liberdades públicas e as exigências da ética. Hoje em dia, em várias partes do mundo, as liberdades universitárias e os conhecimentos críticos são os alvos das políticas "iliberais" e obscurantistas. Sua defesa é nossa responsabilidade coletiva, como pesquisadores, como intelectuais, como cidadãos.

\section{Referências}

BALZAC, Honoré de. Ilusões perdidas. São Paulo: Companhia das Letras, 2011.

BORGES, Jorge Luis. Biblioteca pessoal. Lisboa: Quetzal, 2014.

BORGES, Jorge Luis. Funes, o memorioso. In: BORGES, Jorge Luis. Ficções (1944). São Paulo: Companhia das Letras, 2015. p. 99-108. 
BORGES, Jorge Luis. Euvres complètes. Paris: Gallimard, 1993. 2 v.

BOURDIEU, Pierre. Meditações pascalinas. Rio de Janeiro: Bertrand Brasil, 2001.

BRAUDEL, Fernand. História e Ciências Sociais: a longa duração. In: NOVAIS, Fernando A.; SILVA, Rogério F. da (org.). Nova História em perspectiva. São Paulo: Cosac Naify, 2011.p. 87-127.

BRAUDEL, Fernand. História e Sociologia. In: BRAUDEL, Fernand. Escritos sobre a história. São Paulo: Perspectiva, 1992. p. 91-114.

CERTEAU, Michel de. A escrita da história. Rio de Janeiro: Forense Universitária, 2008.

CHARTIER, Roger. Inscrever e apagar: cultura escrita e literatura (séculos XI-XVIII). São Paulo: Ed. Unesp, 2006.

FOUCAULT, Michel. Nietzsche, a genealogia e a história. In: FOUCAULT, Michel. Microfísica do poder. Rio de Janeiro: Graal, 1979. p. 15-38.

FOUCAULT, Michel. A ordem do discurso: aula inaugural no Collège de France, pronunciada em 2 de dezembro de 1970. São Paulo: Loyola, 2012.

FOUCAULT, Michel. A vida dos homens infames. In: FOUCAULT, Michel. Ditos e escritos: estratégia, poder-saber. Rio de Janeiro: Forense universitária, 2006. v. 4, p. 203-222.

FREUD, Sigmund. Nota sobre o 'Bloco Mágico' (1925). In: FREUD, Sigmund. Obras completa. São Paulo: Companhia das Letras, 2011. v. 16, p. 267-274.

GINZBURG, Carlo. O fio e o rastro: verdadeiro, falso, fictício. São Paulo: Companhia das Letras, 2017.

GREENBLATT, Stephen. Shakesperean negotiations. Berkeley: University of California Press, 1988.

HEIDEGGER, Martin. Ser e tempo. Campinas: Ed. Unicamp; Petrópolis: Vozes, 2012.

KOSELLECK, Reinhart. Estratos do tempo: estudos sobre história. Rio de Janeiro: Contrapunto: Ed. PUC-Rio, 2014.

LIBRILLOS de memoria. In: Diccionario de la lengua castellana. Madrid: Real Academia Espanhola, 1734.

MICHON, Pierre. Vidas minúsculas. São Paulo: Estação Liberdade, 2004.

NORA, Pierre. Entre memória e história: a problemática dos lugares. Projeto História: Revista do Programa de Estudos Pós-Graduados de História, São Paulo, p. 7-28, 1993.

NORA, Pierre. Lieux de mémoire. Paris: Gallimard, 1984-1992. 7 v. 
RICOEUR, Paul. Memória, história, esquecimento. 2003. Disponível em: http://www.uc.pt/fluc/uidief/textos_ricoeur/memoria_historia. Acesso em: 19 nov. 2019.

RICOEUR, Paul. A memória, a história, o esquecimento. Campinas: Ed. da Unicamp, 2007.

RICOEUR, Paul. Tempo e narrativa. São Paulo: Martins Fontes, 2011. 3 v.

ROSA, Hartmut. Aceleração: a transformação das estruturas temporais na Modernidade. São Paulo: Ed. Unesp, 2019.

ROSA, Hartmut. Alienation and acceleration: towards a critical theory of late-modern temporality. Aarhus: Aarhus University Press, 2010.

SCHWOB, Marcel. A cruzada das crianças e vidas imaginárias. São Paulo: Hedra, 2011.

SUPIOT, Alain. La gouvernance par les nombres. Paris: Fayard, 2015.

TZIMINADIS, João Lucas Faco. Modernidade dessincronizada: aceleração social, destemporalização e alienação: uma entrevista com Hartmut Rosa. Revista Estudos de Sociologia, Araraquara, v. 22, n. 43, p. 365-383, jul./dez. 2017. Disponível em: https://periodicos.fclar.unesp.br/estudos/article/view/10462/7140. Acesso em: 19 nov. 2019.

VIRILIO, Paul. Minha língua estrangeira é a velocidade, é a aceleração do real. [Entrevista cedida a] Guilherme Soares dos Santos. Le Monde Diplomatique Brasil, 3 jun. 2011. Disponível em: https://diplomatique.org.br/minha-lingua-estrangeira-e-avelocidade-e-a-aceleracao-do-real/. Acesso em: 1 maio 2019.

VIRILIO, Paul. Velocidade e acidente integral: entrevista de PaulVirilio. [Entrevista cedida a] Fernando Eichenberg. 2000. Disponível em:

https://acervoclaudioulpiano.com/2018/04/24/velocidade-e-acidente-integral-entrevistade-paul-virilio/. Acesso em: 1 maio 2019.

VIRILIO, Paul. Velocidade e política. São Paulo: Estação Liberdade, 1996.

YERUSHALMI, Yosef Hayim. Zakhor: história judaica e memória judaica. Rio de Janeiro: Imago, 1992.

Submetido em: 04/07/2019

Aprovado em: 12/12/2019 